\title{
PRAKTIK PENYIMPANAN DAN PEMBUANGAN OBAT DALAM KELUARGA
}

\author{
Meidia Savira, Firmansyah Ardian Ramadhani, Urfah Nadhirah, Silvy Restuning Lailis, Enrico Gading \\ Ramadhan, Kholidah Febriani, Muhammad Yusuf Patamani, Dian Retno Savitri, Mohd Ridhuan Awang, \\ Miranda Wisnu Hapsari, Nabela Nailiatu Rohmah, Aileen Syifa Ghifari, Moch Davit Abdul Majid,
} Frederic Grorio Duka, Gesnita Nugraheni*

Departemen Farmasi Komunitas, Fakultas Farmasi, Universitas Airlangga Gedung Nanizar Zaman Joenoes Kampus C, Jl. Ir. Soekarno, Surabaya 60115, Indonesia

E-mail: gesnita-n@ff.unair.ac.id

\begin{abstract}
ABSTRAK
Penyimpanan obat harus disesuaikan dengan karakteristik terkait stabilitas untuk menjaga agar senyawa aktif dapat tetap bekerja dengan optimal dalam tubuh saat digunakan. Selain penyimpanan, hal yang masih menjadi perhatian adalah pembuangan obat dengan tepat. Obat berpotensi mencemari lingkungan apabila tidak dibuang dengan cara yang tepat. Akan tetapi, masih banyak masyarakat yang belum mengerti bagaimana cara menyimpan dan membuang obat. Penelitian ini bertujuan untuk mengetahui bagaimana praktik masyarakat, faktor yang mempengaruhi, serta peran keluarga dalam penyimpanan dan pembuangan obat di rumah. Penelitian ini merupakan penelitian cross-sectional dengan metode pengambilan sampel accidental sampling dengan kriteria inklusi berusia lebih dari 18 tahun dan tinggal bersama dengan keluarga. Sebanyak 140 responden berpartisipasi pada survei yang dilakukan. Hampir seluruh responden menyimpan obat di rumah $132(94,3 \%)$ dan 19 responden $(13,6 \%)$ diantaranya menyimpan obat kedaluarsa. Hampir separuh responden 60(42,9\%) menyimpan obat di tempat yang mudah dijangkau oleh anak-anak. Selain itu, lebih dari separuh responden 81(57,9\%) tidak membuang obat dengan benar. Secara umum, praktik responden dalam manajemen obat di rumah termasuk dalam kategori sedang $71(66,4 \%)$. Karakteristik responden yang berpengaruh pada kualitas manajemen obat di rumah adalah usia $(p=0,023)$ dan tingkat penghasilan $(p=0,045)$. Hasil dari penelitian menunjukkan bahwa masih kurangnya praktik penyimpanan dan pembuangan obat di masyarakat dengan benar, sehingga diperlukan edukasi lebih lanjut kepada masyarakat terkait penyimpanan dan pembuangan obat yang benar.
\end{abstract}

Kata kunci: DAGUSIBU, penyimpanan obat, pembuangan obat, penyimpanan obat, pembuangan obat

\begin{abstract}
Drug storage should be done properly to ensure its stability to keep the active compound gives maximum therapeutic effect. Beside storage, other important thing in drug management at home is the disposal of the drugs. Drugs potentially have direct negative environmental impact if it is not disposed properly. In spite of that, there are many people who did not understand the proper way to store and dispose medicines. The goals of this research are to identify factors that influence and family's role in medicine's storage and disposal. This research was a cross-sectional study with accidental sampling method. Inclusive criteria in this research are people who age 18 or above and live with their family. One hundred and forty participants took this survey. Most of the participants stored their medicines in their houses 132(94.3\%) and 19 participants (13.6\%) kept expired medicines. Almost half of the participants 60(42.9\%) stored their medicines in a place that was easily reached by children. In spite of that, more than half of the participants $81(57.9 \%)$ did not dispose the medicines in a proper way. Generally, participants' practice in drug management in family belong to average category $75(67.0 \%)$. Characteristics of the participants which were influenced the quality of drug management in family were age $(p=0.023)$ and income rate $(p=0.045)$. From this result we could conclude that the proper practice of storage and disposal of medicines was still need to be improved. Education intervention related to storage and disposal of medicine in a proper way is needed.
\end{abstract}

Keywords: DAGUSIBU, drug storage, drug disposal, drug storage practices, drug disposal practices 


\section{PENDAHULUAN}

Obat yang disimpan di rumah dapat merupakan obat yang sengaja disimpan untuk kondisi darurat dan sisa dari pengobatan sebelumnya. Obat sisa ini disimpan karena masyarakat merasa sayang untuk membuang dan ingin menggunakannya lagi jika gejala kembali muncul lain waktu (Kemenkes RI, 2007). Berdasarkan Hasil Riset Kesehatan Dasar tahun 2013 menunjukkan bahwa sebanyak 103.860 rumah tangga atau 35,2\% dari 249.959 rumah tangga di Indonesia menyimpan obat untuk swamedikasi. Dari 103.860 rumah tangga yang menyimpan obat, proporsi $35,7 \%$ diantaranya menyimpan obat keras dan $27,8 \%$ diantaranya menyimpan antibiotik. Hal ini memicu terjadinya masalah kesehatan baru, salah satunya adalah resistensi bakteri. Masyarakat tidak boleh sembarangan menyimpan obat, terlebih obat tersebut yang harus dikonsumsi dengan pengawasan tenaga kesehatan seperti obat keras dan antibiotik (Shantanu Deviprasad and Vijaya Laxman, 2016).

Berlandaskan permasalahan tersebut, Direktorat Jenderal Pelayanan Kesehatan (Yankes, 2017) dibawah naungan Kementerian Kesehatan Republik Indonesia (Kemenkes RI, 2007) berusaha melakukan kegiatan sosialisasi dan promosi tentang cara manajemen obat yang tepat dan rasional dengan metode DAGUSIBU (Dapatkan, Gunakan, Simpan, dan Buang Obat) dengan benar. Dari keempat poin dalam manajemen obat, seringkali ditemukan masalah utama yang terdapat pada penyimpanan dan pembuangan obat. Berdasarkan penelitian di China, faktor-faktor yang mempengaruhi pengelolaan obat dalam rumah tangga adalah faktor usia, jenis kelamin, dan pekerjaan (Huang et al. 2019).

Masalah penyimpanan obat tidak hanya terkait golongan obat yang disimpan, namun juga mengenai bahaya akibat penyimpanan tersebut. Lama waktu dan suhu penyimpanan dapat memberikan dampak pada stabilitas dan konsentrasi obat. Hal yang harus diwaspadai adalah potensi perubahan konsentrasi obat dapat berakibat pada perbedaan perkiraan dampak toksisitas obat. Konsentrasi obat dapat meningkat atau menurun tergantung pada kondisi penyimpanannya (Kemenkes RI, 2007).

Selain penyimpanan, masalah obat yang lain adalah pembuangan obat. Berdasarkan penelitian yang telah dilakukan (Aeshah et al. 2017), sebagian besar pasien rawat jalan di rumah sakit tidak membuang obat dengan benar. Masalah yang dapat timbul akibat pembuangan obat yang tidak benar adalah senyawa obat dapat mengontaminasi air dalam tanah, sehingga banyak senyawa obat yang ada dalam aliran air dengan kadar yang tidak terukur karena belum ada alat yang dapat mendeteksi banyaknya kontaminasi obat dalam air tanah (NACWA, 2005).

Upaya pemerintah untuk menangani masalah pengelolaan obat di rumah tangga telah diwujudkan dengan GERMAS (Gerakan Masyarakat Hidup Sehat) yang bertujuan agar masyarakat dapat berperilaku sehat dengan harapan akan berdampak pada kesehatan, lingkungan yang bersih, dan penurunan biaya pengobatan. Di dalam GERMAS, terdapat GEMA CERMAT yang berfokus pada sosialisasi DAGUSIBU dan menunjuk kader di masyarakat dengan tujuan untuk memperbaiki pola pengelolaan obat dalam masyarakat (Kemenkes RI, 2016).

Penelitian ini dilakukan sebagai upaya untuk mendukung program pemerintah dalam melaksanakan GERMAS. Tujuan dari penelitian ini adalah untuk mengetahui profil penyimpanan dan pembuangan obat di keluarga, peran anggota keluarga dalam manajemen obat di rumah, profil kualitas pengelolaan obat, dan menganalisis faktor yang mempengaruhi manajemen obat di rumah. Hasil dari penelitian ini dapat digunakan sebagai sumber informasi mengenai manajemen obat yang benar terkait penyimpanan dan pemusnahan obat dalam keluarga.

\section{METODE PENELITIAN}

Penelitian ini merupakan penelitian observasional dengan pendekatan cross sectional. Pengambilan sampel penelitian dilakukan dengan cara non-random yaitu teknik accidental sampling. Populasi penelitian adalah seluruh warga Kelurahan Pucang Sewu dengan kriteria inklusi berusia lebih dari 18 tahun dan tinggal bersama keluarga.

Perhitungan besar sampel minimal digunakan rumus dari jumlah survei rerata tak terbatas (Zainuddin, 2014) didapatkan 97 sampel penelitian.

$$
n=(Z a)^{2} \frac{S^{2}}{E^{2}}
$$

Keterangan :

$\mathrm{n} \quad=$ jumlah sampel

$\mathrm{Z} \alpha=$ standar distribusi normal $\alpha$ tertentu

$\mathrm{S} \quad$ = simpangan baku (hasil dari penelitian sebelumnya)

$\mathrm{E} \quad=$ penyimpangan mutlak yang ditoleransi terhadap harga rata-rata populasi $(\mu)$ 


\section{Pengambilan Data}

Pengambilan data dilakukan dengan cara survei menggunakan instrumen intervieweradministered questionnaire. Peneliti membuat sejumlah pertanyaan melalui kuesioner yang diajukan kepada responden. Pertanyaan dibacakan oleh peneliti, dan jawaban pertanyaan dari responden diisikan dalam kuesioner. Pertanyaan yang diajukan meliputi data demografi responden, praktik responden dalam menyimpan dan membuang obat, peran anggota keluarga dalam manajemen obat, dan persepsi terhadap fasilitas pembuangan obat.

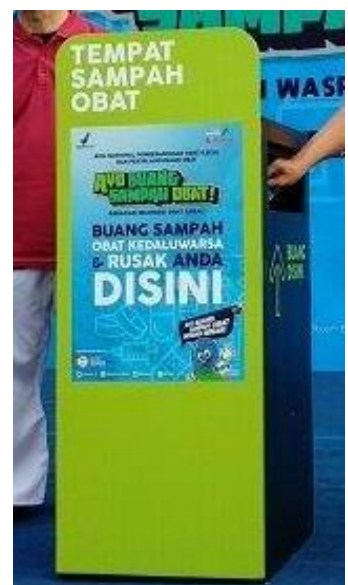

Gambar 1. Tempat Sampah Obat

Sebelum memasuki pertanyaan terkait persepsi responden terhadap penyediaan fasilitas pembuangan obat, peneliti lebih dulu memberikan penjelasan mengenai fasilitas drop box sampah obat di apotek. Penjelasan tersebut meliputi gambar drop box sampah obat dan mekanisme pembuangan obat. Penelitian dilakukan pada tanggal 11-12 September 2019 dan bertempat di Kelurahan Pucang Sewu, Kecamatan Gubeng, Kota Surabaya.

\section{Variabel dan Instrumen Penelitian}

Pengumpulan data dilakukan dengan data primer berupa kuesioner dengan kombinasi pertanyaan terbuka dan pertanyaan tertutup. Peneliti menetapkan kriteria jawaban benar untuk pertanyaan terbuka dalam kuesioner untuk memudahkan penilaian dalam pengolahan data. Kuesioner terbagi menjadi 2 bagian, yaitu bagian I dan bagian II yang merupakan variabel penelitian. Bagian I memuat informasi demografi responden dan Bagian II berisi pertanyaan tentang praktik masyarakat dalam penyimpanan dan pembuangan obat, serta persepsi masyarakat terhadap fasilitas pembuangan obat di apotek.

Tabel 1. Variabel Penelitian

\begin{tabular}{|c|c|c|}
\hline Variabel & Indikator & $\begin{array}{c}\text { Item } \\
\text { Kuesioner }\end{array}$ \\
\hline $\begin{array}{l}\text { Informasi } \\
\text { demografi } \\
\text { responden }\end{array}$ & 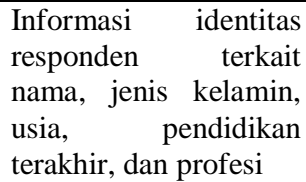 & $\begin{array}{l}\text { Bagian I no } \\
1,2,3,4,5, \\
\text { dan } 6\end{array}$ \\
\hline $\begin{array}{l}\text { Praktik cara } \\
\text { simpan obat }\end{array}$ & $\begin{array}{l}\text { Alasan penyimpanan } \\
\text { obat, } \\
\text { penyimpanan obat, } \\
\text { penandaan dan } \\
\text { penataan dalam } \\
\text { penyimpanan obat }\end{array}$ & $\begin{array}{l}\text { Bagian } \\
\text { nomor } 1,2, \\
3,4,5,6, \\
\text { dan } 10\end{array}$ \\
\hline $\begin{array}{l}\text { Praktik cara } \\
\text { buang obat }\end{array}$ & $\begin{array}{l}\text { Cara pembuangan } \\
\text { obat, } \\
\text { pembuangan obat }\end{array}$ & $\begin{array}{ll}\text { Bagian } & \text { II } \\
\text { nomor } 7,8, \\
9, \text { dan } 10\end{array}$ \\
\hline $\begin{array}{l}\text { Peran } \\
\text { anggota } \\
\text { keluarga }\end{array}$ & $\begin{array}{l}\text { Tugas dan tanggung } \\
\text { jawab anggota } \\
\text { keluarga dalam } \\
\text { penyimpanan dan } \\
\text { pembuangan obat }\end{array}$ & $\begin{array}{l}\text { Bagian } \mathrm{II} \\
\text { nomor } 10\end{array}$ \\
\hline $\begin{array}{l}\text { Persepsi } \\
\text { responden } \\
\text { terhadap } \\
\text { fasilitas } \\
\text { drop box di } \\
\text { apotek }\end{array}$ & $\begin{array}{l}\text { Kesediaan responden } \\
\text { dalam memanfaatkan } \\
\text { fasilitas drop box di } \\
\text { apotek }\end{array}$ & $\begin{array}{lr}\text { Bagian } & \text { II } \\
\text { nomor } & 11 \\
\text { dan 12 } & \end{array}$ \\
\hline
\end{tabular}

(Lutfiyati et al., 2017)

\section{Analisis Data}

Data dianalisis dengan program Statistical Product and Services Solution (SPSS). Data demografi dan profil praktik penyimpanan, pembuangan obat, peran anggota keluarga serta persepsi terhadap fasilitas pembuangan obat di apotek oleh apoteker dianalisis dan disajikan dalam frekuensi dan persentase. Metode analisis inferensial yaitu uji hubungan dan uji beda yang dilakukan uji normalitas.

Klasifikasi kualitas manajemen obat dibagi menjadi tiga kategori yaitu tinggi (skor 6-7), sedang (skor 3-5), dan rendah (0-2). Penentuan skor dilakukan untuk menentukan kategori manajemen obat terkait penyimpanan dan pembuangan oleh masyarakat secara keseluruhan. Indikator penyimpanan dan pembuangan obat yang benar adalah terkait jenis obat yang disimpan, tempat penyimpanan obat, penanggung jawab manajemen obat di rumah tangga, waktu pembuangan obat, dan cara pembuangan obat yang baik dan benar (Huang et al. 2019). 
Tabel 2. Kualitas Pengelolaan Obat dalam Keluarga

\begin{tabular}{|c|c|c|}
\hline No. & Pertanyaan & Jawaban Benar \\
\hline 1 & $\begin{array}{l}\text { Adakah obat kedaluarsa } \text { yang masih } \\
\text { disimpan? }\end{array}$ & $\begin{array}{l}\text { Tidak ada } \\
\text { (Kemenkes RI, 2007) }\end{array}$ \\
\hline 2 & $\begin{array}{l}\text { Apakah Anda membaca kondisi penyimpanan } \\
\text { obat yang tertera pada kemasan obat? }\end{array}$ & $\begin{array}{l}\text { Ya } \\
\text { (Kemenkes RI, 2007) }\end{array}$ \\
\hline 3 & Bagaimana cara Anda menyimpan obat? & $\begin{array}{l}\text { Jauh dari jangkauan anak-anak (Kemenkes } \\
\text { RI, 2007) }\end{array}$ \\
\hline 4 & Adakah penataan obat secara khusus? & $\begin{array}{l}\text { Ya (Memisahkan obat dengan yang } \\
\text { digunakan dan tidak digunakan) (Doucette } \\
\text { et al. 2017) }\end{array}$ \\
\hline 5 & $\begin{array}{l}\text { Apakah ada penandaan khusus pada obat } \\
\text { yang disimpan? (misal: label nama, indikasi) }\end{array}$ & Ya (Doucette et al. 2017) \\
\hline 6 & $\begin{array}{l}\text { Bagaimana cara Anda membuang obat yang } \\
\text { sudah tidak digunakan? }\end{array}$ & $\begin{array}{l}\text { Memisahkan obat dari kemasan primer } \\
\text { (Kemenkes RI, 2007) }\end{array}$ \\
\hline 7 & $\begin{array}{l}\text { Adakah anggota keluarga yang bertanggung } \\
\text { jawab untuk melakukan manajemen } \\
\text { (penyimpanan dan pembuangan) obat dalam } \\
\text { keluarga? } \\
\text { Indikator tugas : } \\
\text { a. Memastikan obat tersimpan dalam tempat } \\
\quad \text { yang benar } \\
\text { b. Mengembalikan obat ke tempat } \\
\text { seharusnya } \\
\text { c. Melakukan pengecekan tanggal } \\
\text { kedaluarsa obat } \\
\text { d. Melakukan pembuangan obat } \\
\text { e. Penataan obat }\end{array}$ & $\begin{array}{l}\text { Ada yang bertanggung jawab, dengan } \\
\text { melakukan manajemen obat sesuai } \\
\text { indikator tugas. (Doucette et al. 2017) }\end{array}$ \\
\hline
\end{tabular}

\section{Skoring}

Skoring dilakukan dengan indikator pertanyaan dalam Tabel 2. Penilaian skor tiap poin pertanyaan bernilai sama. Skor tinggi didapatkan jika responden menjawab pertanyaan dengan benar.

\section{HASIL DAN PEMBAHASAN}

Setelah dilakukan penelitian mengenai perilaku responden terhadap manajemen obat, diperoleh data demografi dari 140 responden.

Tabel 3. Profil Demografi 140 Responden

\begin{tabular}{lll}
\hline \hline & Karakteristik & \multicolumn{1}{c}{ Persentase } \\
\hline \multirow{2}{*}{ Kenis } & Laki-Laki & $29(20,7 \%)$ \\
\cline { 2 - 3 } Usia & Perempuan & $111(79,3 \%)$ \\
\cline { 2 - 3 } & 18-40 Tahun & $49(35 \%)$ \\
\cline { 2 - 3 } & 41-60 Tahun & $67(47,8 \%)$ \\
\hline Pendidikan & $\leq$ SD & $24(17,5 \%)$ \\
\cline { 2 - 3 } & SMP & $44(31,4 \%)$ \\
\cline { 2 - 3 } & SMA & $25(17,9 \%)$ \\
\cline { 2 - 3 } & Perguruan Tinggi & $57(40,7 \%)$ \\
\hline Profesi & Non Kesehatan & $14(10,0 \%)$ \\
\cline { 2 - 3 } & Kesehatan & $138(98,6 \%)$ \\
\hline Penghasilan & $\leq$ Rp500.000 & $47(33,6 \%)$ \\
\cline { 2 - 3 } & Rp500.001 - Rp1.000.000 & $23(16,4 \%)$ \\
\cline { 2 - 3 } & Rp1.000.001-Rp2.500.000 & $48(34,4 \%)$ \\
\cline { 2 - 3 } & Rp2.500.001- Rp5.000.000 & $21(15 \%)$ \\
\cline { 2 - 3 } & Rp5.000.000 & $1(0,7 \%)$ \\
\hline \hline
\end{tabular}

Sejumlah 28 responden dari total 140 orang pada beberapa variabel tidak dimasukkan karena tidak memiliki pengalaman dalam penyimpanan dan pembuangan obat sehingga 
Tabel 4. Profil Manajemen Obat di Keluarga

\begin{tabular}{|c|c|c|}
\hline \multicolumn{2}{|c|}{ Karakteristik Perilaku } & $\mathrm{n}(\%)$ \\
\hline \multicolumn{3}{|c|}{ Alasan penyimpanan obat } \\
\hline A & Pengobatan & $34(24,3 \%)$ \\
\hline B & Persediaan & $98(70,0 \%)$ \\
\hline $\mathrm{C}$ & Tidak menyimpan obat & $8(5,7 \%)$ \\
\hline \multicolumn{3}{|c|}{ Terdapat obat kedaluarsa yang disimpan } \\
\hline A & Ada & $19(13,6 \%)$ \\
\hline B & Tidak & $113(80,7 \%$ \\
\hline $\mathrm{C}$ & Tidak menyimpan obat & $8(5,7 \%)$ \\
\hline \multicolumn{3}{|c|}{ Membaca kondisi penyimpanan obat pada kemasan } \\
\hline A & Membaca & $75(53,6 \%)$ \\
\hline $\mathrm{B}$ & Tidak membaca & $60(42,9 \%)$ \\
\hline $\mathrm{C}$ & Tidak menyimpan obat & $5(3,6 \%)^{*}$ \\
\hline \multicolumn{3}{|c|}{ Cara penyimpanan obat } \\
\hline A & Terhindar dari anak-anak & $72(51,4 \%)$ \\
\hline B & Terjangkau oleh anak-anak & $60(42,9 \%)$ \\
\hline $\mathrm{C}$ & Tidak menyimpan obat & $8(5,7 \%)$ \\
\hline \multicolumn{3}{|c|}{ Penataan obat secara khusus } \\
\hline A & Memisahkan obat yang sering dan jarang digunakan & $31(22,1 \%)$ \\
\hline B & Tidak menata obat secara khusus & $101(72,1 \%)$ \\
\hline $\mathrm{C}$ & Tidak menyimpan obat & $8(5,7 \%)$ \\
\hline \multicolumn{3}{|c|}{ Penandaan khusus dalam menyimpan obat } \\
\hline A & Ada & $49(35,0 \%)$ \\
\hline B & Tidak ada & $83(59,3 \%)$ \\
\hline $\mathrm{C}$ & Tidak menyimpan obat & $8(5,7 \%)$ \\
\hline \multicolumn{3}{|c|}{ Pembuangan obat } \\
\hline A & Pernah dilakukan & $117(83,6 \%)$ \\
\hline B & Tidak pernah dilakukan & $23(16,4 \%)$ \\
\hline \multicolumn{3}{|c|}{ Waktu pembuangan obat } \\
\hline A & Kedaluarsa & $34(24,3 \%)$ \\
\hline $\mathrm{B}$ & Obat rusak & $13(9,3 \%)$ \\
\hline $\mathrm{C}$ & Obat tidak lagi digunakan & $70(50,0 \%)$ \\
\hline $\mathrm{D}$ & Tidak pernah membuang obat & $23(16,4 \%)$ \\
\hline \multicolumn{3}{|c|}{ Cara pembuangan obat } \\
\hline A & Dipisahkan isi dengan kemasan & $36(25,7 \%)$ \\
\hline B & Dibuang langsung ke tempat sampah tanpa pemisahan & $81(57,9 \%)$ \\
\hline $\mathrm{C}$ & Tidak pernah membuang obat & $23(16,4 \%)$ \\
\hline
\end{tabular}

Tabel 5. Peran Anggota Keluarga dalam Manajemen Obat di rumah

\begin{tabular}{|c|c|c|}
\hline & Karakteristik Perilaku & $\mathrm{n}(\%)$ \\
\hline \multicolumn{3}{|c|}{ Terdapat anggota keluarga yang menyimpan obat } \\
\hline A & Ada & $132(94,3 \%)$ \\
\hline $\mathrm{B}$ & Tidak & $8(5,7 \%)$ \\
\hline \multicolumn{3}{|c|}{ Anggota yang bertanggungjawab dalam melakukan manajemen obat } \\
\hline A & Ayah & $9(6,4 \%)$ \\
\hline $\mathrm{B}$ & Ibu & $64(45,7 \%)$ \\
\hline & Anak & $11(7,9 \%)$ \\
\hline
\end{tabular}

Tabel 6. Profil Persepsi Masyarakat terhadap Fasilitas "Take Back Medicine” di Apotek Pernyataan $\mathrm{n}(\%)$

\begin{tabular}{lll}
\hline \multicolumn{3}{l}{ Kebersediaan masyarakat memanfaatkan fasilitas "Take back medicine" di apotek } \\
\hline $\mathrm{A}$ & Bersedia & $82(58,6 \%)$ \\
\hline $\mathrm{B}$ & Tidak bersedia & $57(40,7 \%)$ \\
\hline $\mathrm{C}$ & Missing data & $1(0,7 \%)$ \\
\hline \multicolumn{2}{l}{ Pandangan masyarakat terkait fasilitas "Take back medicine” di apotek } \\
\hline $\mathrm{A}$ & Merasa dimudahkan & $98(70,0 \%)$ \\
\hline $\mathrm{B}$ & Tidak dimudahkan & $41(29,3 \%)$ \\
\hline $\mathrm{C}$ & Missing data & $1(0,7 \%)$ \\
\hline
\end{tabular}


Data hasil survei dibagi menjadi lima kelompok, yaitu; (1) penyimpanan obat, (2) peran anggota keluarga dalam manajemen obat, (3) pembuangan obat, (4) pengaruh profil demografi responden terhadap kualitas praktik manajemen obat di keluarga, dan (5) persepsi masyarakat terhadap fasilitas tempat sampah obat di apotek oleh pemerintah.

\section{Penyimpanan Obat}

Berdasarkan hasil penelitian yang dilakukan, sebanyak 94,3\% responden menyimpan obat di rumah dan $5,7 \%$ tidak menyimpan obat. Dari sejumlah responden yang menyimpan obat, diperoleh, sebanyak $13,6 \%$ diantaranya masih menyimpan obat kedaluarsa. Alasan yang dikemukakan adalah responden tidak mengetahui tentang tanggal kedaluarsa obat. Hal ini bisa disebabkan oleh kurangnya perhatian dari responden terhadap tanggal kedaluarsa obat seperti (1) letak tulisan tanggal kedaluarsa, (2) tidak mendengarkan dengan teliti ketika apoteker menjelaskan tentang informasi obat, (3) kurangnya kemauan responden dalam mencari tahu tentang informasi kedaluarsa obat. Apabila obat yang kedaluarsa dikonsumsi maka terjadi penurunan potensi obat sejumlah 5-50\% (Tribune, 2011). Hal ini bertolak belakang dengan hasil penelitian di India (Pandey et al. 2016) bahwa tidak ada satupun obat kedaluarsa yang disimpan.

Pada pertanyaan terbuka terkait alasan responden menyimpan obat di dalam rumah, didapatkan hasil masyarakat menyimpan obat untuk persediaan $70 \%$, dan pengobatan yang sedang dilakukan $24,3 \%$. Kedua hal tersebut berlawanan dengan penelitian yang telah dilakukan di Ethiopia (Wondimu et al. 2015) dan Iraq (Jassim, 2010) yang mana, persentase responden menyimpan obat sebagai pengobatan yang dilakukan lebih besar dibandingkan sebagai persediaan obat.

Pertanyaan terkait persentase responden yang membaca kondisi penyimpanan obat yang tertera pada kemasan, penelitian menunjukkan bahwa $53,6 \%$ responden membaca kondisi penyimpanan, dan $42,9 \%$ lainnya tidak melakukannya. Hal tersebut sesuai dengan penelitian di China bahwa responden belum cukup memperhatikan kondisi penyimpanan obat. Masalah yang mungkin terjadi akibat kurangnya perhatian terhadap kondisi penyimpanan obat adalah stabilitas obat yang terganggu dan dapat mempercepat degradasi obat sebelum waktunya (Huang et al. 2019).
Penelitian terkait cara penyimpanan obat, diberikan pertanyaan terbuka dengan kriteria jawaban yang ditetapkan adalah penyimpanan yang dijauhkan dari jangkauan anak-anak. Sebanyak $51,4 \%$ responden menyimpan obat sesuai dengan kriteria, dan $42,9 \%$ lainnya tidak melakukannya. Hal ini sesuai dengan penelitian yang dilakukan di Uni Emirat Arab bagian utara tentang tren penyimpanan obat di rumah tangga, lebih dari separuh 168(56,0\%) dari 298 responden yang dilaporkan memiliki home pharmacy untuk menyimpan obat-obatan yang jauh dari jangkauan anak-anak. Penyimpanan obat-obatan yang tidak terorganisir di berbagai tempat di rumah tangga dapat menyebabkan ketidakpatuhan yang tidak disengaja seperti penggunaan obat tanpa anjuran resep dokter, penggunaan antibiotik dan obat bersama dalam keluarga, bahaya bagi kesehatan anak-anak, degradasi yang cepat dan wasted resources. Jadi penyimpanan obat-obatan di lemari obat dan jauh dari jangkauan anak-anak sangat dianjurkan (Sharif et al. 2010).

Terkait penataan obat, diberikan pertanyaan terbuka yang selanjutnya dibandingkan dengan kriteria jawaban yang ditetapkan adalah memisahkan obat yang sedang digunakan dan disimpan untuk persediaan. Sebanyak $72,1 \%$ responden tidak memisahkan obat yang sedang digunakan dengan yang hanya disimpan, dan $22,1 \%$ lainnya sesuai dengan kriteria dari peneliti. Hal ini sesuai dengan penelitian Wondimu et al. (2015) bahwa mayoritas masyarakat di Tigray, Ethiopia menyimpan obat tanpa dipisahkan dan hanya ditempatkan di laci. Penempatan obat dalam satu tempat tanpa dipisahkan antara yang digunakan dan untuk persediaan dapat memungkinkan kesalahan dalam penggunaan obat, dan menyebabkan ketidakpatuhan berupa penggunaan obat bersama tanpa resep (Sharif $e t$ al. 2010).

Penelitian tentang pemberian penanda atau label khusus untuk obat yang disimpan menunjukkan bahwa sebanyak 35\% responden masih memberikan penandaan khusus seperti label nama, indikasi obat dan sebanyak 59,3\% lainnya tidak melakukannya. Hal ini seperti yang tertulis dalam penelitian Wondimu et al. (2015) di Oman bahwa 59\% obat yang disimpan dirumah tidak diberi label yang memadai. Kesadaran masyarakat akan pentingnya memberikan penandaan khusus agar tidak terjadinya kesalahan dalam menggunakan obat bisa dikatakan masih rendah. Padahal pemberian label dapat memudahkan masyarakat dalam menggunakan obat sesuai dengan keluhan yang dihadapi, dan label juga sangat 
meminimalisir resiko salah penggunaan obat karena fungsi obat sudah tertera jelas dalam label.

\section{Peran Anggota Keluarga dalam Manajemen Obat}

Jawaban responden mengenai peran anggota keluarga yang bertanggung jawab untuk melakukan manajemen obat adalah mayoritas responden 91(65,0\%) merespon dengan menyatakan ada yang bertanggung jawab untuk manajemen obat, dan 48(34,3\%) responden menyatakan tidak ada. Adapun yang berperan dalam manajemen obat dikategorikan menjadi 4 , yaitu Ayah, Ibu, Anak, dan Keluarga, dimana persentase mayoritas $64(45,7 \%)$ yang memiliki tanggung jawab adalah Ibu. Manfaat pengaturan obat di rumah (1) obat lebih tertata, (2) kondisi obat tidak ada yang kedaluarsa sehingga memudahkan penggunaan obat saat dibutuhkan, (3) meningkatkan kepatuhan pasien. Seluruh anggota keluarga seharusnya berperan dalam manajemen obat.

Berdasarkan hasil tersebut, responden dengan jawaban "Ya" yang melakukan manajemen obat seperti memastikan obat tersimpan dalam tempat yang benar, mengembalikan obat ke tempat yang seharusnya, melakukan pengecekan tanggal kedaluarsa obat, melakukan pembuangan obat dan melakukan penataan obat, hasilnya tercantum dalam Gambar 2.

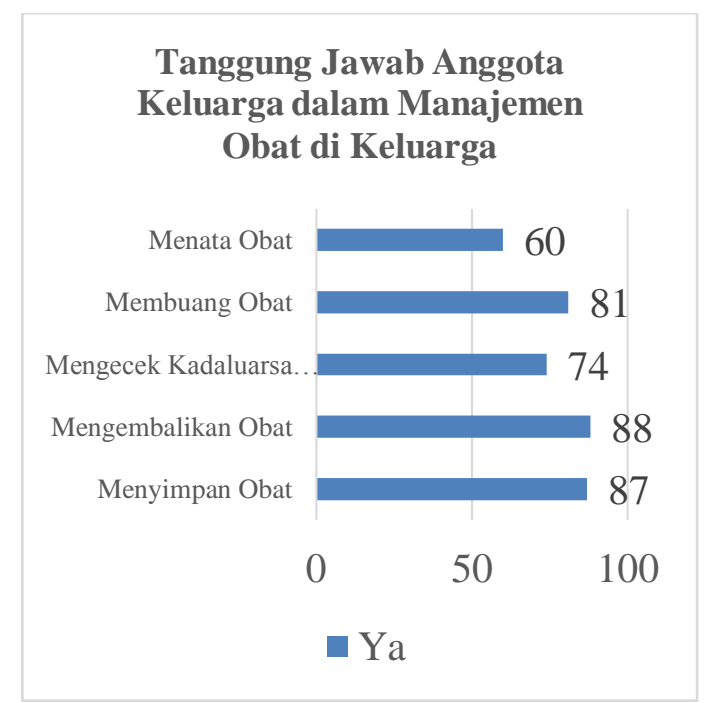

Gambar 2. Grafik Hasil Survei Pola Manajemen Obat $(\mathrm{n}=91)$

Berdasarkan tabel di atas diketahui bahwa jumlah jawaban yang ada melebihi jumlah responden, hal ini dikarenakan satu orang responden dapat menjawab lebih dari satu jawaban pada poin pola manajemen obat.
Diketahui mayoritas responden mengembalikan obat ke tempat yang seharusnya setelah digunakan dengan jumlah jawaban "ya" sebanyak 88 dan menyimpan ke tempat yang seharunsya dengan jumlah jawaban "ya" sebanyak 87.

Perolehan data hasil menunjukkan profil yang serupa dengan penelitian Doucette et al., (2016) tentang model penerapan manajemen obat dalam keluarga, dimana elemen dari rumah tangga meliputi peran keluarga, tanggung jawab dan harapan, pengaturan hidup, hubungan interpersonal, norma sosial dan kehadiran sumber daya terkait keuangan dan kesehatan (misalnya status pekerjaan, ketersediaan asuransi kesehatan). Adanya peran keluarga dan perpaduan antara tugas, peralatan dan teknologi dapat meningkatkan kualitas hidup dan terhindar dari efek merugikan dari kesalahan pengelolaan obat. Peran anggota keluarga dalam menajemen obat terutama penyimpanan dan pembuangan obat di rumah tangga dapat meningkatkan jaminan keamanan pengunaan obat sesuai dengan penelitian.

(1) Pembuangan Obat

Pertanyaan terkait pembuangan obat memperoleh hasil mayoritas responden $117(83,6 \%)$ menjawab pernah membuang obat, dan sebagian kecil 23(16,4\%) lainnya tidak pernah. Terkait waktu responden membuang obat, sejumlah responden menjawab jika ada waktu. Alasan responden untuk tidak pernah membuang obat dikarenakan dalam rumah tangga tersebut sudah ada yang biasa bertugas dalam pengaturan obat. Hal ini sesuai dengan penelitian oleh Azmi et al. (2017) yang menyatakan bahwa pengetahuan responden terkait pembuangan obat sudah tinggi, dimana hanya 5\% (48/902) responden yang tidak pernah membuang obat.

Untuk penelitian terkait cara membuang obat, diberikan pertanyaan dengan kriteria jawaban benar yang ditetapkan adalah pembuangan obat dengan dipisahkan dari kemasan primernya. Berdasarkan hasil penelitian, lebih dari separuh responden $81(57,9 \%)$ tidak membuang obat dengan cara yang benar, sebagian kecil responden $36(25,7 \%)$ membuang obat dengan benar, dan $23(16,4 \%)$ responden tidak pernah membuang obat. Pada umumnya masyarakat membuang obat langsung ke tempat sampah tanpa memisahkan obat terlebih dahulu.

Penelitian oleh Kusturica et al. (2012) di Serbia juga menunjukkan hal yang serupa, dimana pembuangan obat langsung ke tempat sampah relatif tinggi. Perilaku membuang sampah obat langsung ke tempat sampah 
berdampak buruk bagi lingkungan karena dapat mencemari air tanah, sungai, danau atau bahkan air minum. Tetapi pembuangan obat langsung ke tempat sampah merupakan cara pembuangan obat yang umum di lingkungan rumah tangga baik di perkotaan maupun pinggiran kota (Tong et al. 2011).

\section{Pengaruh Profil Demografi Responden Terhadap Kualitas Praktik Manajemen Obat di Keluarga}

Penentuan skor dilakukan untuk menilai praktik manajemen obat dalam keluarga yang meliputi penyimpanan dan pembuangan obat warga Bagong Ginayan. Berdasarkan hasil penelitian, diketahui hanya $10,70 \%$ dengan total 12 responden yang telah melakukan praktik dengan baik, sedangkan $67 \%$ dengan total 75 responden diketahui telah melakukan praktik dengan cukup baik dan 22,30\% dengan total 25 responden belum melakukan praktik yang baik. Data hasil dikelompokkan menjadi diagram pada Gambar 3.

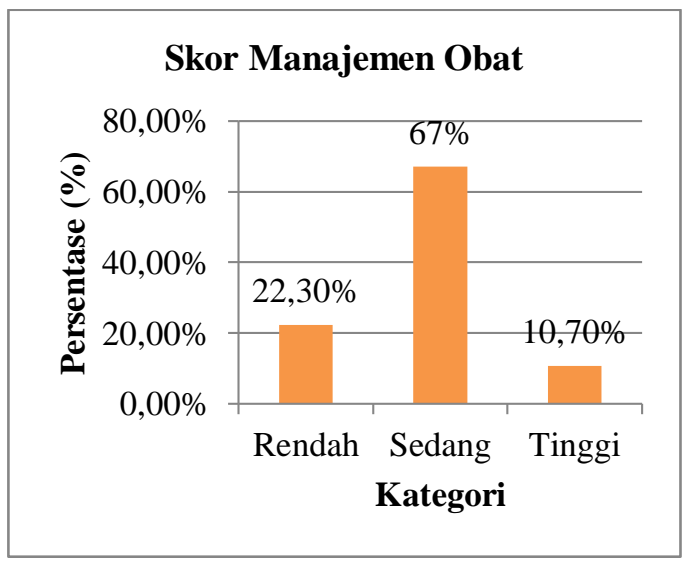

Gambar 3. Diagram hasil skor manajemen obat

Tabel 7. Faktor yang mempengaruhi kualitas praktik manajemen obat di keluarga

\begin{tabular}{|c|c|c|c|}
\hline No. & Variabel & $\begin{array}{l}\text { Rerata } \\
\text { skor }\end{array}$ & $p$ \\
\hline \multirow[t]{3}{*}{1} & \multicolumn{2}{|c|}{ Jenis Kelamin } & 0,291 \\
\hline & Laki-laki & 3,90 & \\
\hline & Perempuan & 3,47 & \\
\hline \multirow[t]{4}{*}{2} & \multicolumn{2}{|c|}{ Tingkat Pendidikan } & 0,338 \\
\hline & SD & 3,30 & \\
\hline & SMP-SMA & 3,69 & \\
\hline & Perguruan tinggi & 3,36 & \\
\hline \multirow[t]{5}{*}{3} & \multicolumn{2}{|c|}{ Tingkat penghasilan } & $0,045^{*}$ \\
\hline & $\mathrm{I}(\leq \mathrm{Rp} 500.000)$ & 3,14 & \\
\hline & $\begin{array}{l}\text { II } \quad(\text { Rp500.000- } \\
\text { Rp1.000.000) }\end{array}$ & 4,00 & \\
\hline & $\begin{array}{l}\text { III(Rp1.000.000- } \\
\text { Rp2.500.000) }\end{array}$ & 3,49 & \\
\hline & $\begin{array}{l}\text { IV(Rp2.500.000- } \\
\text { Rp5.000.000) }\end{array}$ & 4,06 & \\
\hline
\end{tabular}

\begin{tabular}{llcc}
\hline \hline & Rata-rata $^{1}$ & 3,55 & $0,081^{*}$ \\
\hline 4 & \multicolumn{2}{c}{ Usia } & 0,075 \\
\cline { 2 - 3 } & $18-40$ tahun & 3,20 & \\
\cline { 2 - 3 } & $41-60$ tahun & 3,70 & \\
\cline { 2 - 3 } & $61-80$ tahun & 4,07 & \\
\cline { 2 - 3 } & Rata-rata & & \\
\hline
\end{tabular}

Keterangan : Uji korelasi dengan Spearman test; tingkat penghasilan I dengan II berbeda $(p=0,018)$; tingkat penghasilan I dengan IV berbeda $(p=0,032)$

Pengolahan data demografi responden menggunakan SPSS dilakukan untuk mengetahui korelasi antara variabel dan skor. Diperoleh hasil data sebagai Tabel 7. Total responden keseluruhan adalah sebanyak 140 responden, dengan 28 data tidak digunakan karena responden tidak menjawab pertanyaan dengan lengkap. Analisis menggunakan 112 data menunjukkan pada demografi tingkat penghasilan dengan skor diperoleh perbedaan signifikan $(<0,05)$ dan semua data berdistribusi tidak normal sehingga digunakan analisis non parametrik. Selanjutnya dilakukan posthoc analysis dengan uji beda Mann-Whitney dengan kelompok tingkat penghasilan I berbeda dengan kelompok tingkat penghasilan II dan IV. Uji korelasi dengan Spearman test menunjukan adanya korelasi antar variabel pada tingkat penghasilan dengan skor $p=0,081 ; \mathrm{r}=0,166$ dan usia dengan skor $p=0,023 ; \mathrm{r}=0,214$. Kekuatan korelasi ditentukan berdasarkan nilai koefisien korelasi versi De Vaus (De Vaus, 2002). Nilai koefisien korelasi signifikansi sebesar 0,166 dan 0,214 menunjukkan kekuatan korelasi rendahsedang.

Dari data tersebut, dapat disimpulkan bahwa tingkat penghasilan dan usia memiliki pengaruh pada perolehan skor. Penghasilan kategori IV (Rp 2.500.000,00 - Rp 5.000.000,00) yang merupakan penghasilan tertinggi juga menghasilkan perolehan skor yang tinggi. Usia kategori III (61-80 tahun) yang merupakan kategori usia tertua memiliki perolehan hasil skor yang tinggi pula. Pengaruh tingkat penghasilan karena semakin tinggi tingkat penghasilan, maka semakin mudah masyarakat mendapat informasi dan praktik terkait penyimpanan dan pembuangan obat. Sedangkan pengaruh usia adalah dengan semakin dewasa usia, maka kemungkinan sudah memiliki banyak pengalaman dalam menggunakan obat, dan kemampuan berpikir pun turut berkembang menjadi semakin bijak sehingga dapat menyikapi penyimpanan dan pembuangan obat dengan benar.

(2) Persepsi masyarakat terhadap fasilitas tempat sampah obat di apotek oleh pemerintah 
Dari hasil pengolahan data, diperoleh lebih dari separuh responden $82(58,6 \%)$ bersedia memanfaatkan fasilitas untuk membuang obat di apotek. Responden mendukung program dari BPOM yang bertujuan mengurangi penyalahgunaan obat yang telah dibuang. BPOM bekerja sama dengan apotek membuat program kesehatan yaitu penyediaan fasilitas tempat sampah khusus untuk obat. Sedangkan sebagian responden $57(40,7 \%)$ tidak bersedia untuk memanfaatkannya. Hampir setengah dari total responden tidak bersedia memanfaatkan fasilitas tersebut karena adanya rasa malas untuk pergi ke apotek dan masih memilih untuk membuang di tempat sampah sendiri.

Sebagian besar responden 98(70,0\%) merasa akan dimudahkan dengan adanya fasilitas tempat sampah obat di apotek, sedangkan sebagian kecil 41(29,3\%) lainnya tidak. Hal tersebut sesuai dengan penelitian Husain et al. (2017) yang menyebutkan bahwa lebih dari separuh responden 246(58,29\%) dalam penelitian di Karachi, Pakistan merasa dimudahkan dan bersedia memanfaat fasilitas pembuangan obat oleh apoteker.

Hasil penelitian menunjukkan bahwa peran anggota keluarga dalam manajemen obat di rumah mayoritas adalah Ibu. Peneliti merekomendasikan bahwa setiap anggota keluarga dapat memiliki peran dalam manajamen obat dengan memiliki pengetahuan yang cukup untuk manajemen obat. Persepsi responden terhadap program pembuangan sampah obat di apotek oleh apoteker adalah masyarakat merasa terbantu dengan adanya fasilitas tersebut, namun untuk memanfaatkan fasilitas tersebut masyarakat merasa keberatan, karena harus menuju apotek lebih dulu. Rekomendasi peneliti adalah pemerintah dapat memberikan bantuan tempat sampah obat yang dikoordinasikan melalui RT/RW untuk memudahkan masyarakat dalam membuang obat. Pengelolaan pembuangan sampah obat selanjutnya dilakukan oleh apoteker. Selanjutnya, dimusnahkan secara massal oleh BPOM. Hal ini dapat memudahkan masyarakat, mengingat antusias masyarakat terhadap program ini, sehingga masyarakat dapat ikut berpasrtisipasi terhadap keamanan pembuangan obat di keluarga.

Pada penelitian di Nigeria (Zakni et al. 2016), peneliti menyarankan agar apoteker memberikan pengetahuan kepada masyarakat mengenai cara penyimpanan obat yang benar. Selain itu, untuk memperbaiki pembuangan obat di masyarakat dapat menggunakan 'medicinetake-back-programme' yaitu obat yang sudah tidak digunakan oleh masyarakat dapat dikembalikan ke rumah sakit atau apotek, dan fasilitas kesehatan tersebut menjamin obat dibuang oleh lembaga yang berwenang dengan cara yang benar.

\section{KESIMPULAN}

Berdasarkan hasil penelitian yang dilakukan, praktik penyimpanan dan pembuangan obat dari masyarakat yang baik dan benar masih kurang. Penyimpanan masih dilakukan dengan kondisi yang tidak sesuai untuk obat, dan pembuangan obat masih dilakukan dengan membuang langsung pada tempat sampah tanpa pemisahan sehingga perlu dilakukan pemberian edukasi lebih lanjut tentang praktik penyimpanan dan pembuangan obat untuk masyarakat.

Persepsi masyarakat terkait program pembuangan sampah obat di apotek adalah masyarakat merasa keberatan untuk pemanfaatan fasilitas drop box karena harus menuju apotek lebih dulu sehingga diharapkan tersedia tempat sampah obat yang didistribusikan hingga tingkat RT/RW agar masyarakat lebih memanfaatkan secara maksimal.

\section{DAFTAR PUSTAKA}

Azmi, A, Hani, AH, Rayf, A, Faiz, B, Noha, A, Mohamed, O 2017, 'Patients knowledge and attitude toward the disposal of medications', Journal of Pharmaceutics, 17(1), pp. 1-9.

Badan Pengawas Obat dan Makanan (BPOM) 2012, Peraturan Kepala Badan Pengawas Obat dan Makanan Republik Indonesia Nomor HK.03.1.33.12.12.8195 Tahun 2012 tentang Penerapan Pedoman Cara Pembuatan Obat yang Baik, BPOM, Jakarta.

De Vaus, D 2002, Surveys in Social Research. 5th Edition, Routledge, London.

Departemen Kesehatan RI 2006, Pedoman Penggunaan Obat Bebas dan Bebas Terbatas, Departemen Kesehatan, Jakarta.

Doucette, WR, Vinel, S, Pennathur, P 2017, 'Initial development of the Systems Approach to Home Medication Management (SAHMM) model', Research in Social and Administrative Pharmacy, 13(1), pp. 39-47.

Ikatan Apoteker Indonesia 2014, Pedoman Pelaksanaan Gerakan Keluarga Sadar Obat Pengurus Pusat Ikatan Apoteker Indonesia', Pengurus Pusat Ikatan Apoteker Indonesia, Jakarta.

Gitawati, R 2014, 'Pattern of household drug storage', National Public Health Journal, 9(1), pp. 27.

Huang, Y, Wang, L, Zhing, C, Huang, S 2019, 
'Factors influencing the attention to home storage of medicines in China', BMC Public Health, 19(1), pp. 1-10.

Husain, T, Farooqi, S, Khan, M, Humayoon, R 2017, 'Medication disposal; household practices in karachi, pakistan. need for a medication take-back program', The Professional Medical Journal, 24(09), pp. 1380-1386.

Jassim, A 2010, 'In-home drug storage and selfmedication with antimicrobial drugs in Basrah, Iraq', Oman Medical Journal, 25(2), pp. 79-87.

Kemenkes RI 2007, Pedoman penggunaan obat bebas dan bebas terbatas, Ditjen Bina Kefarmasian dan Alat Kesehatan, Kemenkes RI, Jakarta, pp. 9-14.

Badan Pengawas Kesehatan 2013, Riset Kesehatan Dasar 2013. Kementerian Kesehatan RI, Jakarta.

Direktorat Jenderal Kesehatan 2017, Dagusibu Dapatkan Gunakan Simpan Buang (viewed 25 April 2018), http://yankes.depkes.go.id/read-dagusibu-dapatkan-gunakan-simpan-buang-1792.html

Kusturica, MP, Sabo, A, Tomic, Z, Horvat, O, Solak, Z 2012, 'Storage and disposal of unused medications: Knowledge, behavior, and attitudes among Serbian people', International Journal of Clinical Pharmacy, 34(4), pp. 604-610.

Kummerer, K, Hempel, M 2010, Preface and scope of the book, Green and Sustainable Pharmacy, pp. 165-178.

Lutfiyati, H, Yuliatuti, F, Dianita, PS 2017, Pemberdayaan Kader Pembina Kesejahteraan Keluarga dalam Penerapan (Dapatkan, Gunakan, Simpan, dan Buang).
(1), pp. 9-14

Nisak, M, Atika, SN, Pradita, SPY, Astin, MKI, Li, F, An, DN, Pratita, FPP, Dwi WP, Deka, AAP, Shofiatur, R 2016, 'Profil penggunaan dan pengetahuan antibiotik pada ibu-ibu', Jurnal Farmasi Komunitas, 3(1), pp. 12-17.

Shantanu, DP, Vijaya, LC 2016, 'Cross sectional study of factors associated with home storage of medicines', Journal of Chemical and Pharmaceutical Research, 8(8), pp. 1114-1120.

Sharif, SI, Bustami, HA, Haddah, Li, Khalil, DS 2010, 'Trends of home drug storage and use in different regions across the northern united arab emirates', Medical Principles and Practice, 19(5), pp. 355-358.

Tong, AYC, Peake, BM, Braund, R 2011, 'Disposal practices for unused medications around the world', Environment International, 37(1), pp. 292-298.

Tribune, T 2011, Expired drugs To take or not to take viewed 27 June 2018, https://www.tribuneindia.com/2011/201112 08/edit.htm\#6

Wondimu, A, Molla, F, Demeke, B, Eticha, T, Assen, A, Abrha, S, Melkam, W 2015. 'Household storage of medicines and associated factors in tigray region, northern ethiopia', Plos One, 10(8), pp. e0135650

Zakni, B, Auta, A, Dayom, DW, Buba, Z 2016, 'Assessment of the storage and disposal of medicines in some homes in Jos north local government area of Plateau State, Nigeria', Tropical Journal of Pharmaceutical, 15(5), 989-993.

Zainuddin, M 2014, Metode Penelitian Kefarmasian dan Kesehatan, Airlangga University Press, Surabaya. 